\title{
Detecting Individual Tree Position and Height Using Airborne LiDAR Data in Chollipo Arboretum, South Korea
}

\author{
Eunji $\mathrm{Kim}^{1}$, Woo-Kyun Lee ${ }^{2,}$, Mihae Yoon ${ }^{3}$, Jong-Yeol Lee ${ }^{2}$, Eun Jung Lee ${ }^{2}$, and Jooyeon Moon ${ }^{2}$ \\ ${ }^{1}$ Department of Climate Environment, Korea University, Seoul, Korea \\ ${ }^{2}$ Department of Environmental Science and Ecological Engineering, Korea University, Seoul, Korea \\ ${ }^{3}$ E3, Seoul, Korea
}

Received 2 July 2015, revised 25 March 2016, accepted 29 March 2016

\begin{abstract}
Forest carbon is accurately quantified by observing individual tree positions and heights. This paper proposes a novel algorithm for individual tree detection using Light Detection and Ranging (LiDAR) data in the Chollipo arboretum, South Korea. The proposed algorithm does not need to specify a proper window size for operation, taking advantage over the mostly used local maxima (LM) filtering for forest analysis. Four hundred twenty-nine treetops were detected and the average height and standard errors were $12.74 \pm 0.24 \mathrm{~m}$. Reference data were collected from two sources for verifying accuracy: field survey and visual interpretation. Overall, the result was overestimated but showed relatively high accuracy. The field survey detected $87 \%$ of the trees with a coefficient of determination $\left(\mathrm{R}^{2}\right)$ and root mean square error (RMSE) of 0.77 and $1.57 \mathrm{~m}$, respectively. The accuracy index (AI), which examines the correspondence between LiDAR detected and visually interpreted trees, was $91 \%$. The average tree height error between on-site and LiDAR derived data was $-1.42 \pm 0.64 \mathrm{~m}$ and between visually interpreted and LiDAR derived data was $-0.84 \pm 0.10 \mathrm{~m}$. This study emphasized the choice of algorithm and its parameters depending on forest conditions may influence the individual tree detection result. By comparing our work against previous studies, we found the tree location and height identification accuracy could be improved if different algorithms were used for different types of forests, as well as the LiDAR point density with each algorithm. This study suggests that more accurate individual tree detection could be obtained with different applications based on forest conditions.
\end{abstract}

Key words: LiDAR, Forest, Carbon stock, Individual tree detection algorithm, Climate change

Citation: Kim, E., W. K. Lee, M. Yoon, J. Y. Lee, E. J. Lee, and J. Moon, 2016: Detecting individual tree position and height using Airborne LiDAR data in Chollipo Arboretum, South Korea. Terr. Atmos. Ocean. Sci., 27, 593-604, doi: 10.3319/TAO.2016.03.29.01(ISRS)

\section{INTRODUCTION}

Forests' adaptation to climate change is critical, as they are the only global carbon sink recognized by the international community (KFS 2009). According to the Intergovernmental Panel on Climate Change (IPCC) $5^{\text {th }}$ Assessment Report (AR5), Agriculture, Forestry, and Other Land Use (AFOLU) sectors contributed $24 \%$ of total anthropogenic emissions in 2010 (IPCC 2014; Tubiello et al. 2015). While all sectors excluding AFOLU increased Greenhouse Gas (GHG) emissions, land use sectors including forestry maintained similar levels as before due to decreasing deforestation and increasing reforestation. Therefore, forests are expected to be a net sink at the end of the $21^{\text {st }}$ century. More

\footnotetext{
* Corresponding author

E-mail:leewk@korea.ac.kr
}

reliable forest carbon stock estimation is required at the national and global scale to reduce GHG emissions efficiently (KFS 2013; IPCC 2014). Field measurement of all individual trees is required for accurate forest carbon quantification. However, measuring carbon in forests is time-consuming, labor-intensive, and expensive. It is essential to apply remote sensing techniques for forest carbon quantification to solve these issues (Popescu 2007; Park et al. 2011).

Aerial optical imagery has been widely applied for decades in the previous forest investigation studies (Jakubowski et al. 2013). It is difficult to quantify forest stocks because optical imagery collects spectral information in 2D (Cui et al. 2012). This is especially true for dense forests. Light Detection and Ranging (LiDAR) is used to observe individual tree information from remotely sensed data (Hyyppä et al. 2001; Persson et al. 2002; Chen et al. 2006). Leckie et al. 
(2003) mentioned that LiDAR could reduce large amounts of commission errors in falsely identified trees in open stands compared to optical imagery (Chen et al. 2006). LiDAR has the ability to acquire vertical tree information such as tree height using geo-registered 3D points (Kwak et al. 2007). With improved high point density (pts $\mathrm{m}^{-2}$ ), many studies have recently performed individual tree level analysis using program based algorithms and image segmentation methods as well as plot-level analysis (St-Onge et al. 1999; Persson et al. 2002; Clark et al. 2004, 2011; Chave et al. 2005). Accurate individual tree detection is directly associated with more reliable forest carbon quantification.

Most recent studies on tree detection can be categorized to five main methods: local maxima (LM) filtering (Popescu et al. 2002), region-growing (Kim et al. 2010), valley-following (Gougeon 1995), watershed segmentation (Kwak et al. 2007), and the integrated methods relying on LM (Eysn et al. 2015). LM filtering has been widely used to detect trees in remotely sensed images (Pouliot et al. 2002; Park et al. 2011). A LM was identified when the specified pixel value was higher than all neighboring pixels within a specified window size (Park et al. 2014). However, it is quite difficult to define an optimal window size using forest conditions. Inadequate window size could result in commission errors when the window size is too small and omission errors when the window size is too large (Blundell 2008).

This paper proposes an individual tree detection algorithm coded using FORTRAN program language to overcome the LM-filtering disadvantage, which needs to specify the window size. This algorithm was used to detect until it finds the tree top from the starting pixels regardless of the window size. After the first treetop is found, the algorithm is re-used from the first tree top pixel to identify the second treetop. In addition, we emphasize the forest condition such as climatic zone, species composition, forest structure, forest age, and so on when pouring algorithms.

Theoretically, a higher LiDAR point density could be more efficient for tree position and height detection (Eysn et al. 2015). Eysn et al. (2015) selected the different forest types using different algorithms for comparison accuracy. They found that the pilot area Pellizzano, with a maximum LiDAR point density of $121 \mathrm{pts} \mathrm{m}^{-2}$, showed the worst detection results among all of the 8 pilot areas even with such extremely high point density. Thus, we found that LiDAR point density is not the only indicator that determines the tree detection result. Pelizzano consists of multi-storied mixed forest that has a large amount of trees with different height layers. In contrast, the best detection result occurred in a single-storied coniferous forest (Eysn et al. 2015). Warner et al. (1998) and Park et al. (2014) also mentioned that various types of forest conditions could result in distinctly different results due to different crown morphology characteristics. Vauhkonen et al. (2012) referred to their previous published benchmark as not applicable to all forest types, and limited to some parts of a forest. Rahman and Gorte (2009) generated different datasets using the crown shape, density of understory vegetation, and forest type as pouring the same algorithm with equal LiDAR point density. The highest accuracy occurred with understory vegetation with a low-density pure forest. At this point, this study indicated that analysis accuracy could be applied differentially depending on which algorithm was applied under the various forest conditions.

This study is detected individual trees using a FORTRAN program based algorithm. A few individual tree detection researches are analyzed using their study area forest type. We compared the differences in each result based on the different forest conditions. By understanding the difference in results between these researches under different forest conditions, effective algorithm usage can be determined, leading to more accurate tree detection results. Such higher accuracy detection results will contribute to reliable forest carbon stock quantification in the future.

\section{MATERIALS AND METHODS}

\subsection{Study Area}

The study area is located at Chollipo arboretum in South Korea (see Fig. 1a; coordinates: longitude 126 8'59”'E, latitude $36^{\circ} 47^{\prime} 52^{\prime \prime} \mathrm{N}$ ) covering approximately 7.9 ha situated from $0-58 \mathrm{~m}$ above sea level. The average temperature in the study area was $12.6^{\circ} \mathrm{C}$ with average precipitation of $721 \mathrm{~mm}$. The arboretum holds more than 16000 plants and tree species. It is the biggest arboretum in South Korea. According to the $5^{\text {th }}$ forest type map, based on sampling plot data from 2006 - 2010 (KFS 2013), the forest area is 3.3 ha with mixed forest. Even though the arboretum is characterized as a mixed forest type, there are a larger proportion of coniferous trees than deciduous trees. The diameter class of this study area is small which implies that the study area is comprised of small trees. The age class of the study area is class V (crown occupation rate of stand at 45 - 50 years old higher than 50\%). The forest density is middle level (crown occupation rate of high trees higher than $51-70 \%)$. The overall forest condition of this study area is mono-storied mixed forest with decurrent crown shape (see Table 1).

\subsection{Airborne LiDAR Data}

We acquired LiDAR data on 16 December 2007 with a point density of 11 points per square meter $\left(\mathrm{pts}^{-2}\right)$. The minimum and maximum LiDAR data elevations were 0.8 and $58.4 \mathrm{~m}$, respectively (see Fig. 1b). Terrasolid's TerraScan software (http://terrasolid.fi) with MicroStation 8.1 was used to pre-process the LiDAR data. Up to four echoes per pulse were recorded by the sensor. Raw LiDAR data was classified into the following two groups: first returns and last returns for the raw data rasterization. Digital Surface Model 
(DSM) and Digital Terrain Model (DTM) were generated from the first returns and last returns data, respectively. The Canopy Height Model (CHM) was built with a spatial resolution of $1 \mathrm{~m}$ by subtracting corresponding DTM $1 \mathrm{~m}$ grid elevation from DSM $1 \mathrm{~m}$ grid (Kwak et al. 2010). The Triangulated Irregular Network (TIN) interpolation method was performed to generate DSM, DTM, and CHM in the ArcGIS 10.1 program. This process converted LiDAR points into raster format (Kwak et al. 2010; Jakubowski et al. 2013).

\subsection{Individual Tree Detection Using LiDAR Data}

An algorithm coded using FORTRAN program language overcame the LM filtering method disadvantage to detect the individual trees and heights. LM filtering has mostly been used for tree detection requires a specified window size. Incorrect window size results in low analysis accuracy (Park et al. 2014). However, this algorithm detects until its finds the first treetop (e.g., $i, j=3,5$ ) from the starting point (e.g., $i, j=0,0$ ). Afterwards the algorithm is re-utilized from the first tree top pixel (e.g., $i, j=3,5$ ) to identify the second tree top (e.g., $i, j=9,12$ ). Compared to LM filtering, which finds the tree top only inside the moving window, this algorithm has the advantage in detecting a tree regardless the specified window size. This algorithm was developed under the following three assumptions: (1) each individual tree has only one tree top; (2) a tree top represents the highest elevation of the tree; (3) canopy height is lower toward the outside from the top. Based on the above mentioned assumptions, the lowest inflection point would be identified as a tree top. This algorithm performs two processes: data pre-processing and data analysis (see Fig. 2).

\subsubsection{Data Pre-Processing}

The proposed individual tree detection algorithm starts from CHM data, which indicates the relative height pixel between the first and last return with a raster format. We generated CHM data with $1 \mathrm{~m}$ spatial resolution (see section 2.2) converted into digital numbers with the text format. Due to complicated scan pattern, some objects floating in the air could interrupt the reflected electromagnetic wave acquisition (Yoon 2015). Such interruptions could result in incorrect detection of an objective or an incorrect return to the sensor, resulting in a pixel value of 0 or abnormal value. For calibration, abnormal pixel values are replaced using the mean value of normal surrounding pixel values in a $3 \times 3 \mathrm{~m}$ window using the following Eq. (1) (Yoon 2015).

$a^{\prime}=\left(b_{1}+b_{2}+\ldots+b_{7}+b_{8}\right) / N$

$a^{\prime}$ : Calibrated pixel value;

$\mathrm{b}_{1}, \mathrm{~b}_{2}, \ldots, \mathrm{b}_{\mathrm{n}}$ : Normal surrounding values ( $\mathrm{n}=1$ to 8$)$;

$\mathrm{N}$ : Number of normal surrounding values in each window $(\mathrm{N}=8)$.

The laser beam often penetrates the branches, giving the canopy a very rough surface. An optimal smoothing process is essential to overcome this problem. Gaussian filtering was performed to provide a more continuous surface value while eliminating statistical outliers (Brandtberg et al. 2003). Gaussian filtering can effectively eliminate noise in an image by applying the following equation [see Eq. (2); Wang et al. 2004] where $x$ and $y$ represent the distance from the reference pixel in the horizontal and vertical axis, respectively. In addition, $\sigma$ represents standard deviations determining the degree of intensity and weight.

$g(x, y)=\frac{1}{2 \pi \sigma^{2}} e^{-\frac{x^{2}+y^{2}}{2 \sigma^{2}}}$

The reference pixel in a $3 \times 3 \mathrm{~m}$ kernel $(\sigma=3)$ is weighted according to the distance based on Eq. (2) ( $\mathrm{Gu}$ et al. 2010). By adapting this process, systematic errors such as (a)

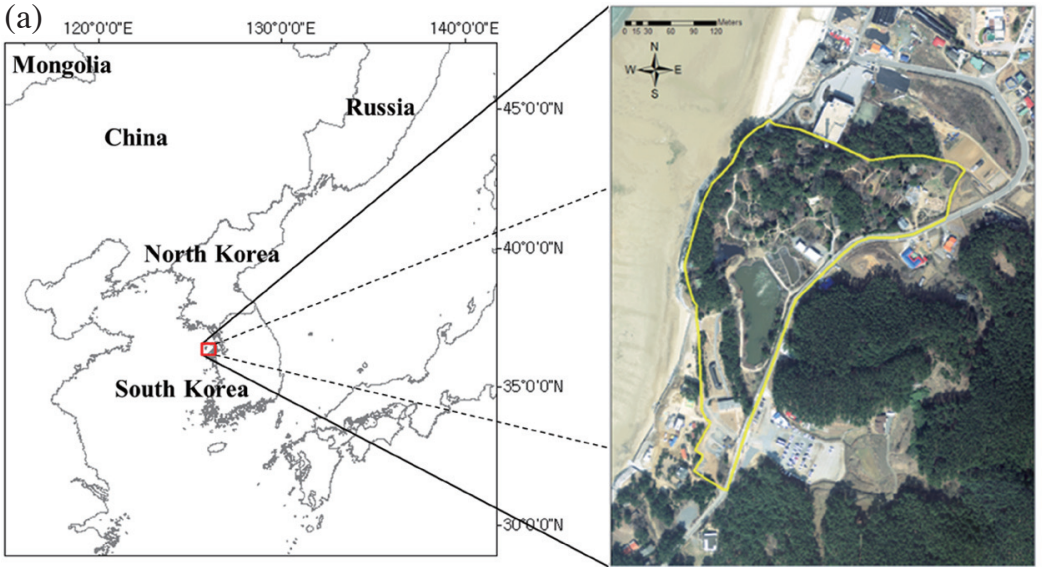

(b)

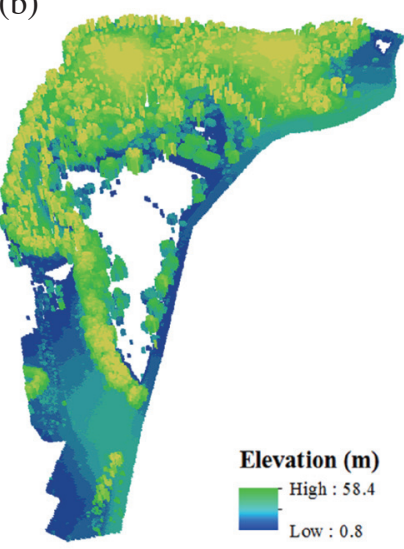

Fig. 1. (a) Study area, (b) LiDAR data. (Color online only) 


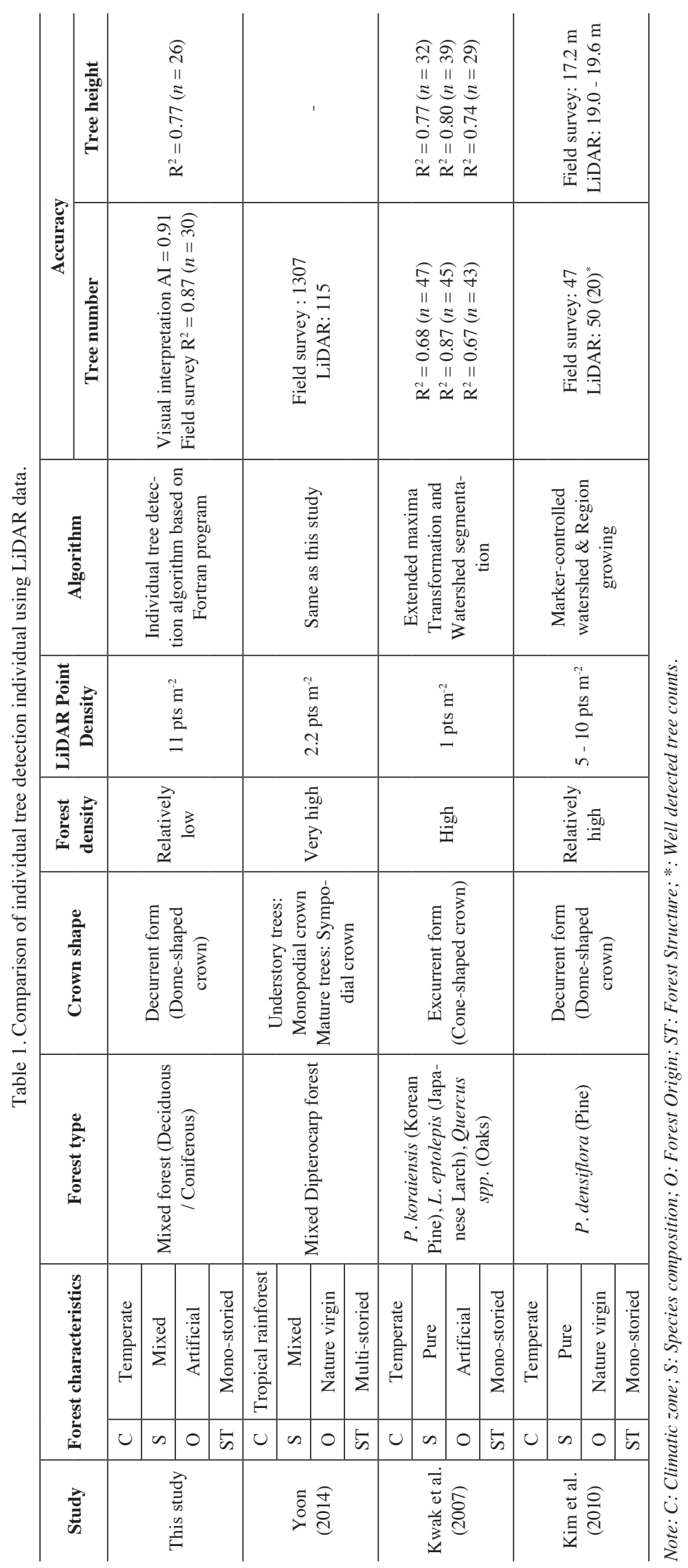




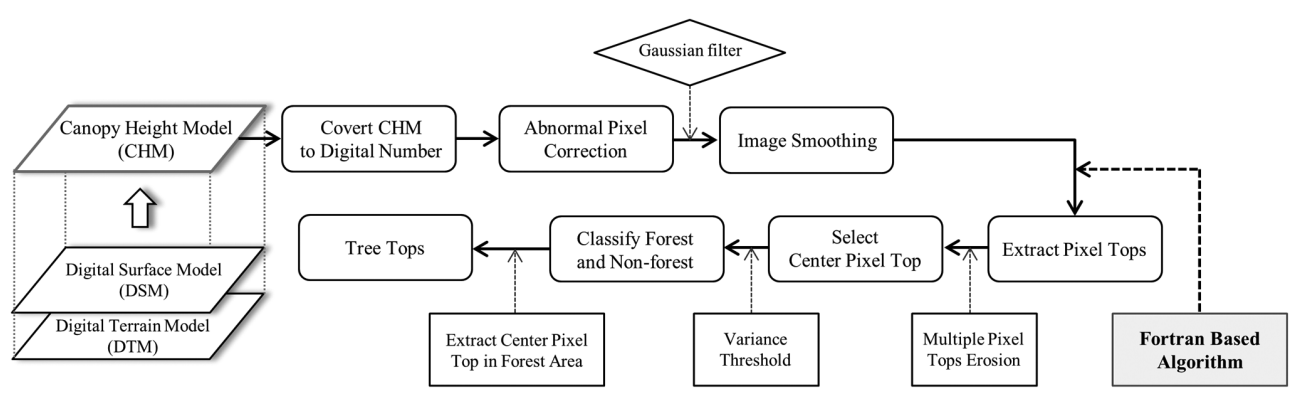

Fig. 2. Overall flow chart of this study.

separating one tree into several trees resulting in the overestimation of the number of individual trees can be avoided (Yoon 2015).

\subsubsection{Data Analysis}

The data analysis process is divided into four parts: (1) pixel top extraction, (2) detecting center pixel tops, (3) forest and non-forest area classification, (4) detecting treetops. As a first step in extracting pixel tops, the algorithm finds the highest pixel from the center pixel as a starting point until it reaches where the adjacent pixel is lower. While the pixel value continuously increases starting from the bottom to the top of the canopy, there is a point where an adjacent pixel value becomes instantly lower than the previous pixel (for example, pixel "A" which is shown in Fig. 3a). Based on the above mentioned algorithm assumption 3 (see section 2.3), we designate pixel "A" as the pixel top. An individual tree could have several pixel tops and not a single pixel. This is why we called pixel "A" a pixel top and not the treetop. This study used a scoring method to find the pixel with the highest value among the neighborhood of pixels (see Fig. 3b). This process operates in four directions: horizontal, vertical, 45 degree, and 135 degree angle. If the center pixel value $(i, j)$ is higher than its neighboring pixel value in the designated direction, the center pixel was given 1 point. If not, the pixel was given 0 point. If the center pixel earned a point in all directions, it would get total of 4 points and be assigned as a pixel top.

The pixel erosion process is designed to detect the highest center pixel tops among multiple pixel tops. The erosion technique is run in the counter clockwise direction four consecutive times $(\mathrm{N} \rightarrow \mathrm{S}, \mathrm{S} \rightarrow \mathrm{N}, \mathrm{E} \rightarrow \mathrm{W}, \mathrm{W} \rightarrow \mathrm{E})$ until it finds the center pixel tops by eroding the adjacent multiple pixel tops from outside to inside. In the next step, the variance value of the $3 \times 3 \mathrm{~m}$ kernel is then calculated. In order to extract only the forest area among the center pixel tops, the optimal variance threshold is specified via trial and error according to the forest structure and tree characteristics in the study area. This value is used to classify the site into forest and non-forest areas. The center pixel tops located in the forest area are consequently designated as treetops.

\subsection{Accuracy Assessment}

The following two reference data sources are used commonly: field survey and visual interpretation (Ke and Quackenbush 2011; Park et al. 2014). Generally, the field survey produces more accurate results than visual interpretation (Ke and Quackenbush 2011). However, the field survey has limitations in time, labor-force and expense compared to visual interpretation. Due to these restrictions, visual interpretation has been used as an alternative to field survey method since the early 1960s (Singh et al. 1986; Ke and Quackenbush 2011). Wang et al. (2004) and Lamar et al. (2005) mentioned that visual interpretation is limited in clearly identifying individual trees when the tree is small and identifying the crown shape due to different morphological characteristics. To overcome the constraints of each method and promote more reliable accuracy assessment, both visual interpretation and field survey are used. Thirty trees with heights ranging from $14-23 \mathrm{~m}$ were randomly chosen and field measured for the accuracy verification. LiDAR derived trees were found and their GPS coordinates obtained using the Montana 650 GPS device. In addition, the individual tree heights were measured. A time difference exists between the LiDAR acquisition date (2007) and field survey date (2014). The annual tree growth rate was applied to redeem this problem. The study area is located in Taean-gun, Chungcheongnam-do. The annual forest growth rate is $4.2 \%$ proposed by Korea Forest Institute. The growth rate was derived from the $5^{\text {th }}$ national forest inventory based on sampling plot data from 2006 - 2010 (KFS 2013). In addition, visual interpretation was performed to overcome the limitation in the number of on-site samples. A randomly assigned circular plot with an area of 0.49 ha was installed to reduce the image acquisition error from seasonality, aerial images acquired in the winter (16 December 2007) and spring (22 March 2014), both used to identify individual trees with spatial resolutions of $25 \mathrm{~cm}$ and $1 \mathrm{~m}$. CHM with $1 \mathrm{~m}$ grid derived from airborne LiDAR images was set as reference data to aid visual segmentation in the 3D-view. 


\section{RESULTS AND DISCUSSION}

\subsection{Detection of Individual Trees and Tree Height}

The mean filter calibrated the abnormal data generated using CHM. Pixels that are 0 or less were replaced using the mean normal surrounding pixel values (see Figs. 4a, b). The Gaussian filtering method provided continuous surface value for image smoothing to prevent two peaks detected for one tree (see Figs. 4c, d).

The individual tree detection algorithm extracted 828 pixel tops from objectives including trees, buildings, etc. Afterwards, the eroding process identified the center pixel among multiple pixel tops in single trees (see Fig. 5a). The average pixel top height was $7.08 \pm 0.24 \mathrm{~m}$ ranging from $0.08-50.72 \mathrm{~m}$. This algorithm was utilized to designate center pixel tops in forest area as a treetop by first calculating the variance and specified optimal variance value via trial and error. Values higher than the threshold of 50 were considered forest areas while values lower than the threshold was considered non-forest areas. Center pixel tops located in the forest area are designated treetops. Four hundred twenty-nine treetops were extracted in this procedure (see Figs. 5b, c). The average tree height is $12.74 \pm 0.24 \mathrm{~m}$ ranging from $4.05-24.87 \mathrm{~m}$ with a standard deviation of $4.97 \mathrm{~m}$. Because the leaf-off period could interrupt analysis the leaf-out time was considered for each canopy. Seasonal effects could influence the growth of coniferous trees more than deciduous trees (Yoon et al. 2006; Lee 2008). Since LiDAR data was acquired during the leaf-off winter months, coniferous trees were visually identified using aerial images to confirm how well they were detected. We checked the coniferous tree detection result using field survey data. As shown in Fig. 5e, relatively high coniferous tree detection accuracy was identified visually despite the seasonal effect (see Figs. 5d, e).

\subsection{Accuracy Verification}

\subsubsection{Accuracy Assessment by Field Survey}

Both individual tree detection and tree height results were evaluated. A range of tree height from $14-23$ m was randomly chosen for the field survey. Out of $30 \mathrm{LiDAR}$ derived trees, 26 were detected through field survey with an approximately $87 \%$ tree detection result. The accuracy rate in this study was higher than that for preceding researches. Yoon (2015) applied the same algorithm in tropical rain forest. However, it only showed $8.8 \%$ detection accuracy. Kim et al. (2010) analyzed at accuracy of 26 and $68 \%$ using region-growing and watershed segmentation based algorithms. Field measured tree height was subsequently verified by targeting tree heights above $14 \mathrm{~m}$ and below $23 \mathrm{~m}$. The coefficient of determination $\left(\mathrm{R}^{2}\right)$ value and root mean square error (RMSE) were 0.77 and $1.57 \mathrm{~m}$, respectively. The average error between LiDAR-predicted and fieldobserved height was $-1.42 \pm 0.64 \mathrm{~m}$. A negative average error value indicated that LiDAR derived trees were overestimated. This could be caused by several factors derived from field survey and LiDAR scan angle. The Haglof VertexIII hypsometer was used in this study with accuracy for distance of $1 \%$ or better for the tree height measurement (Vasilescu 2013). Vasilescu (2013) mentioned that if the hypsometer was correctly calibrated, only one error could be caused by operator accuracy. Depending on where the operator set the sight line on the treetops, accuracy could be different. Hunter et al. (2013) also said that errors associated with the difficulty in designating tree tops may occur, resulting in an underestimation or overestimation of measured tree height. It was reported that the laser scan angle could affect the individual tree detection error. If small trees were located next to bigger trees with few returns, it is difficult to detect them at the same time (Magnussen and Boudewyn 1998; Næsset and Økland 2002; Brandtberg et al. 2003; Holmgren and Persson 2004).

\subsubsection{Accuracy Assessment by Visual Interpretation}

Remotely sensed visual imaging interpretation was conducted to obtain evaluation that is more accurate. A randomly (a)

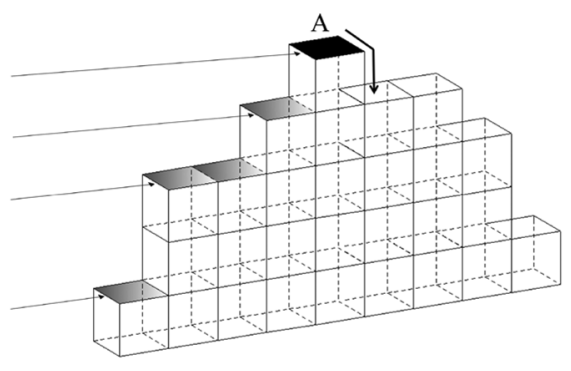

(b)
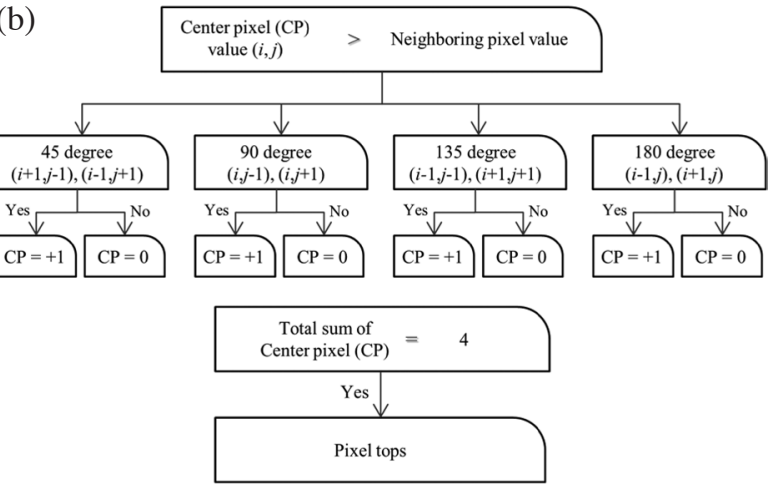

Fig. 3. (a) Arrangement of pixels for the pixel top finding process, (b) detailed pixel tops detection algorithm. 
(a)

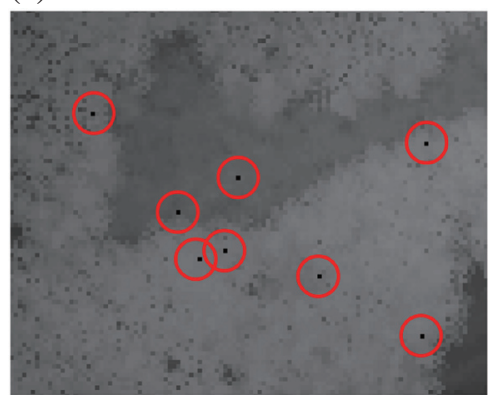

(c)

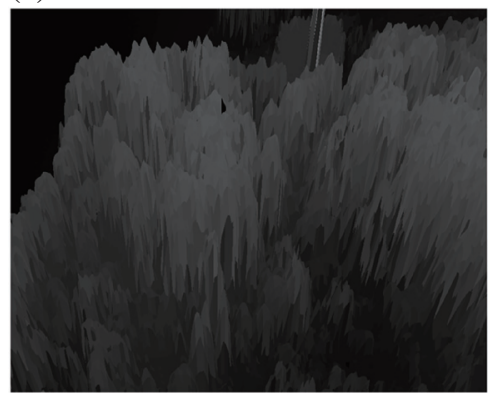

(b)

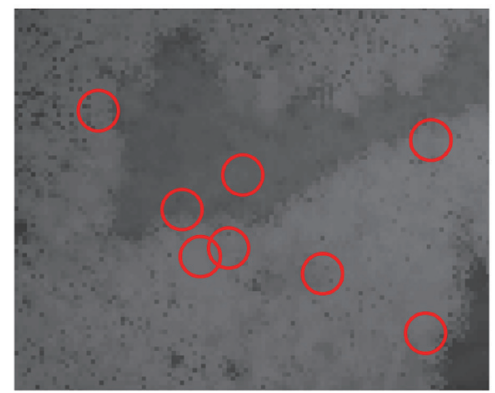

(d)

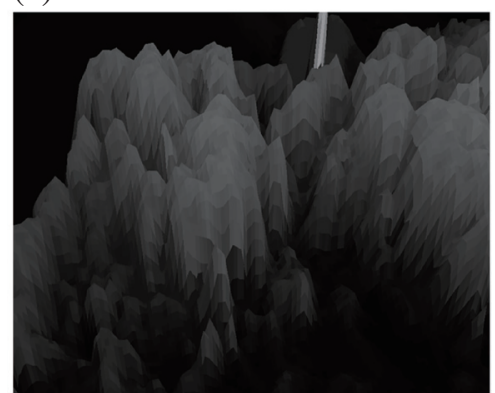

Fig. 4. (a) CHM with abnormal data, (b) abnormal data corrected CHM in 2D-view, (c) abnormal data corrected CHM in 3D-view, (d) smoothed CHM in 3D-view. (Color online only)

(a)

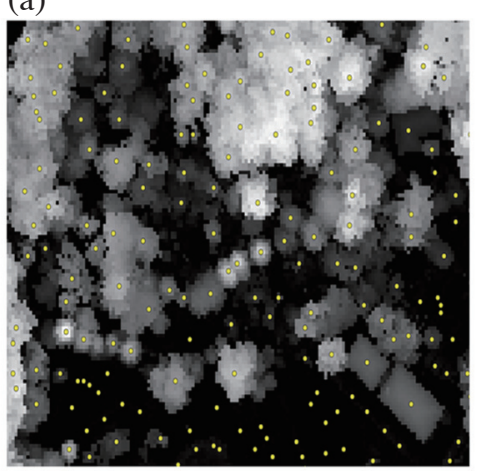

(c)

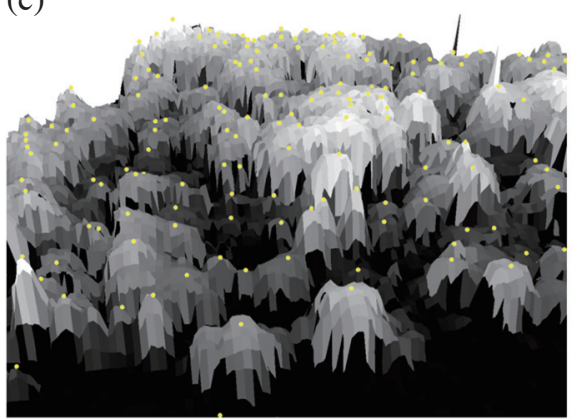

(d) (b)
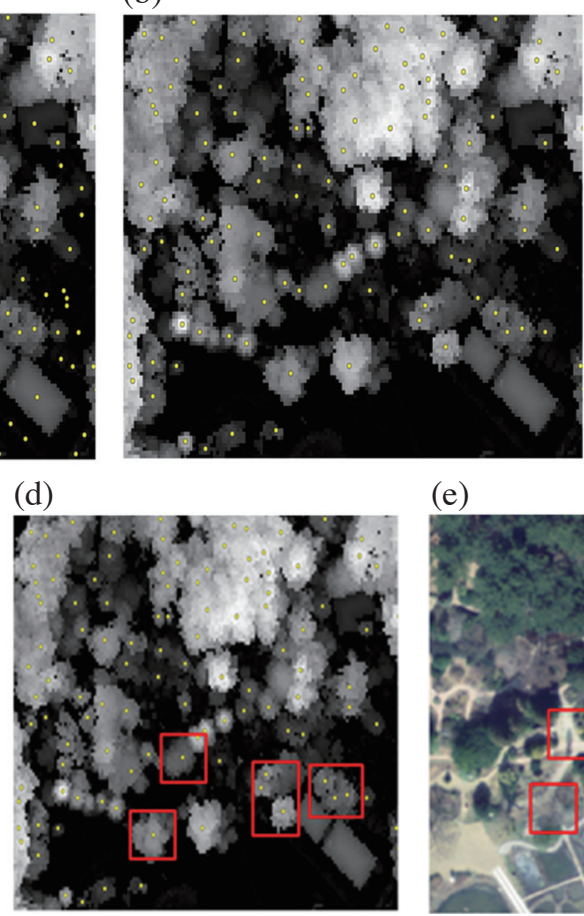

(e)

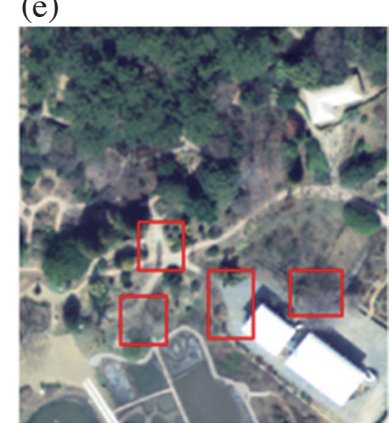

Fig. 5. (a) Extract center pixel tops, (b) extract tree tops, (c) tree tops expressed in three dimensional CHM, (d) coniferous trees in CHM, (e) coniferous trees in aerial images shooting in spring. (Color online only) 
chosen 0.49 ha circular plot, visually segmented using three reference datasets with: aerial images acquired in winter (16 December 2007) with a spatial resolution of $1 \mathrm{~m}$, spring (22 Marcg 2014) with a spatial resolution of $25 \mathrm{~cm}$ in 2D-view, and LiDAR derived CHM were used to delineate the crown for both 2D and 3D-views, as shown in Fig. 6 .

The number of crowns designated to the number of trees in the reference plot. The total number of trees was 104. Visually interpreted data accuracy verification used accuracy index (AI) which is an accuracy index explained by the percentage used to examine the correspondence between LiDAR detected trees and visually interpreted trees (Ke and Quackenbush 2011). This AI defined by Pouliot et al. (2002) represents the overall accuracy, as shown in Eq. (3), where $o$ and $c$ represent the number of omission and commission errors, respectively. $n$ is the total number of reference trees in Eq. (2). When the reference crowns are falsely assigned as multiple tree crowns commission errors occur. Omission errors occur when reference crowns are undetected.

$\mathrm{AI}(\%)=\frac{n-(o+c)}{n} \times 100$

The total number of well-detected trees, falsely detected trees and omitted trees were 95, 3, and 6, respectively. The AI value of detected tree number was approximately $91.35 \%$, with high accuracy between LiDAR derived and visually segmented trees (see Table 2).

Omission errors indicating undetected trees occurred relatively higher than commission errors. This is likely due to the smoothing method and indistinct boundaries. Gaussian filtering used in this study has a tendency to reduce the depth of pits. Therefore, undetected small tree tops often occur (Kim et al. 2010). Secondly, indistinct boundaries between tree crowns in dense forest could result in omission errors (Park et al. 2014). Under such knowledge, forest condition comprehension could lead to more reliable interpretation and accurate results. This issue will be discussed in detail in section 3.3. In most researches using visual interpretation methods for accuracy assessment, treetops were visually interpreted under the subjectivity of the interpreter. However, this can result in lower analysis accuracy depending on the interpreter's judgment accuracy, including the uncertainty of segmenting tree crowns. Therefore, we applied different method to figure out the highest pixel which exists inside the visually interpreted canopy using $1 \mathrm{~m}$ grid CHM. The difference between visually observed and LiDAR-predicted height was $-0.84 \pm 0.10 \mathrm{~m}$, indicating an average error. The visual interpretation result also indicated that tree detection using LiDAR data was overestimated. Consequently, both methods of assessing accuracy showed overestimation. Zhang et al. (2015) mentioned that far-extending branches might lead the identification to fail during the algorithm process. The Gaussian smoothing method selected in this study could also induce overestimation (Zhang et al. 2015). The standard error, standard deviation and range of errors were $0.1,0.97$, and $0-5 \mathrm{~m}$, respectively. We calculated the $\mathrm{R}^{2}$, RMSE, and relative error (RE) values by height. Tree heights were classified into four groups: under 10, 10 - 15, 15 - $20 \mathrm{~m}$, and above $20 \mathrm{~m}$ (see Table 3 ). Their $\mathrm{R}^{2}$ values were $0.65,0.69,0.83$, and 0.62 , respectively.

The tree height group above $20 \mathrm{~m}$ had the lowest accuracy rate, while the group ranging from $15-20 \mathrm{~m}$ had the highest accuracy rate. Theoretically, higher trees should increase the detection accuracy because other trees do not interrupt tall trees. However, compared to other groups, this group gathered in certain parts, causing them to be undetected or merged into one tree. Therefore, high density between big trees might have lowered the accuracy.

\subsubsection{Comparison of Two Results of Accuracy Assessment}

The visual interpretation and field data results were compared using individual trees ranging from $14-23 \mathrm{~m}$. Visual interpretation was performed on all groups but field data was collected only on trees $14-23 \mathrm{~m}$. Under the same condition, $\mathrm{R}^{2}$ values derived from both methods were 0.77 and 0.88 , respectively (see Fig. 7). Field survey generally showed higher accuracy compared to visual interpretation (Ke and Quackenbush 2011). However, the inaccuracy of visual interpretation cannot be ignored. Although visual interpretation accuracy appeared to be higher than field survey, the two methods show similar accuracy because of the difference in sample numbers, 26 and 45. Visual interpretation has high uncertainty because of interpreter subjectivity as well as a larger number of samples than field survey. Furthermore, the study area contained mixed forest dominated by trees even-aged from $45-50$ years old. This could have caused difficulty in identifying tree crowns due to their dome-shape, and not the cone-shaped trees. Our results suggest that a well-trained interpreter and high-resolution aerial images are needed to reduce uncertainties when evaluating LiDAR data using visual interpretation. In addition, interpretation should consider forest characteristics and the acquisition date of aerial images.

\subsection{Comparison with Preceding Researches}

Note that the choice of algorithm and its parameters using forest conditions may considerably affect individual tree detection results. Theoretically, a higher LiDAR point density could be more efficient for tree detection in the forest. Eysn et al. (2015) realized a higher LiDAR point density might not produce more accurate detection results. One of his pilot sites, with 121 pts $\mathrm{m}^{-2}$, showed worse results among all of the 8 sites and it is considered due to the multi-storied mixed 
forest characteristics with a number of trees having different height layers. Few individual tree detection researches and the characteristics of forests for respective studies have been extensively explored. Afterwards, we compared the different results derived from each study and analyzed how forest conditions such as forest structure, crown shape, algorithm, etc. can influence tree detection accuracy.

Generally, individual tree detection algorithms are based on finding treetops under the assumption that the lowest inflection point will be the treetops. It is worth comparing the accuracy because the inflection point could be influenced by the forest condition (see Table 1). Yoon (2015) applied the same algorithm used in this study area on a virgin dipterocarp mixed forest in Brunei. As a result, LiDAR derived individual trees were only 115 that occupied $8.8 \%$ compared to field measured trees. This low accuracy compared to this study was probably caused by different forest conditions. The forest in Yoon's study (2015) is more complex with multistoried tropical rainforest, high forest density, high canopy cover, and morphologically different crown shapes. Smaller and younger dipterocarps in the understory have monopodial crowns while the mature dipterocarps exhibit sympodial (a)

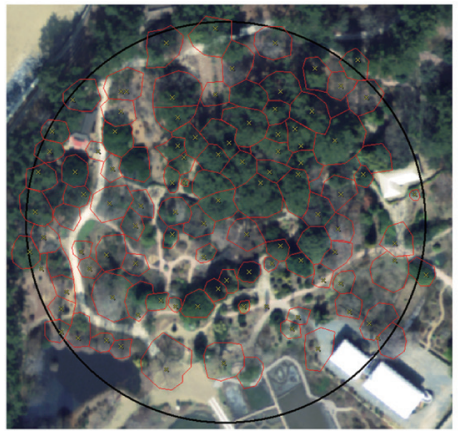

(b)

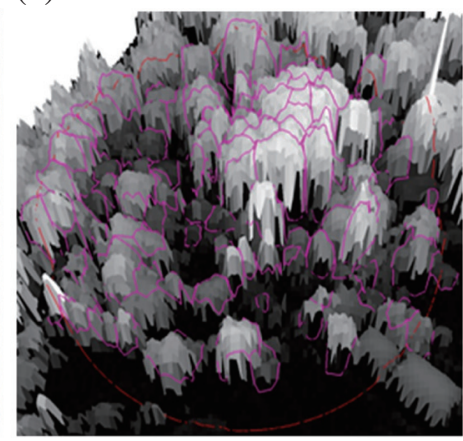

(c)

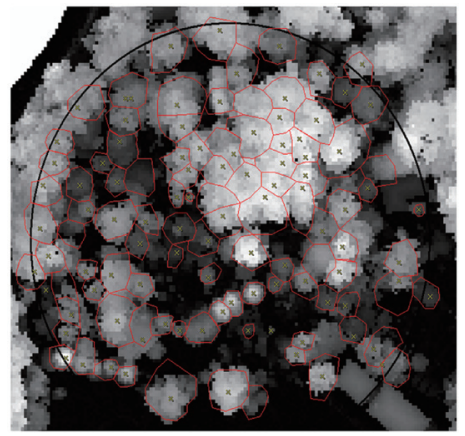

Fig. 6. Segmented tree crown by visual interpretation expressed in (a) aerial image, (b) 2D-view CHM, (c) 3D-view CHM. (Color online only)

Table 2. Accuracy index assessment.

\begin{tabular}{cc}
\hline Reference tree number & $104(99)^{*}$ \\
Well-detected tree number & 95 \\
Commission error & 3 \\
Omission error & 6 \\
$\mathbf{A I}(\boldsymbol{\%})$ & 91.35 \\
\hline Note: *: Numbers of LiDAR derived individ- \\
ual trees.
\end{tabular}

Table 3. Accuracy assessment by tree height between LiDAR derived height and visually interpreted height.

\begin{tabular}{c|cccc}
\hline \multirow{2}{*}{ Accuracy } & \multicolumn{4}{|c}{ Tree height (m) } \\
\cline { 2 - 5 } & $\mathbf{< 1 0}$ & $\mathbf{1 0} \mathbf{- 1 5}$ & $\mathbf{1 5}-\mathbf{2 0}$ & $\mathbf{2 0}$ \\
\hline $\mathrm{R}^{2}$ & 0.65 & 0.69 & 0.83 & 0.62 \\
RMSE (m) & 0.16 & 0.30 & 0.24 & 0.25 \\
RE (m) & 0.12 & 0.22 & 0.17 & 0.16 \\
\hline
\end{tabular}
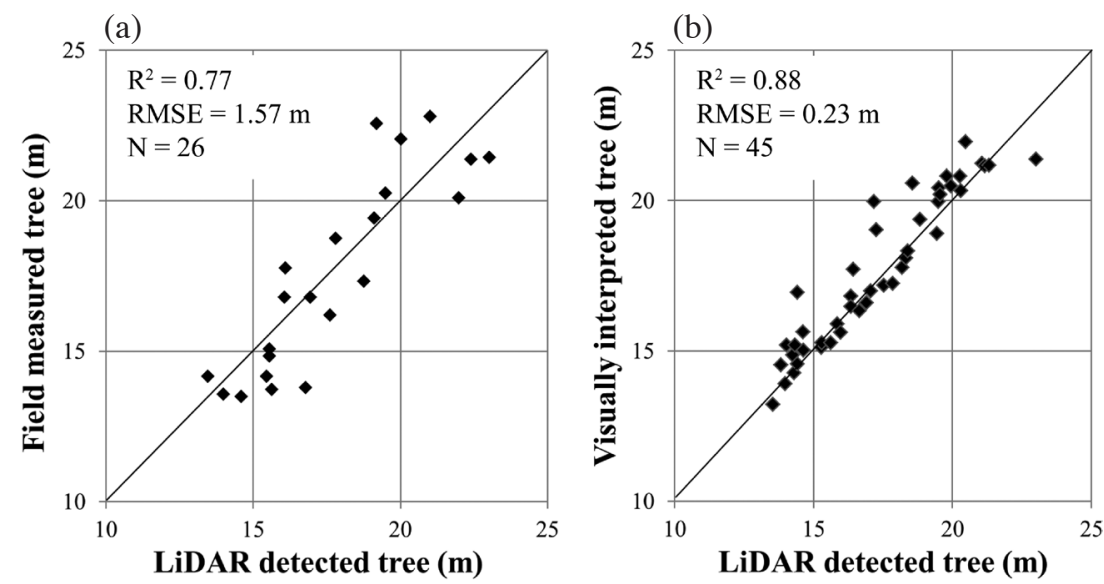

Fig. 7. Accuracy assessment through (a) field survey, (b) visual interpretation. 
crowns with broader crown width than height (Kricher 2011; Yoon 2015). In other words, the crown shape in Yoon's study area can unpredictably change with the stand age, i.e., each tree has various inflection points interrupting the analysis, which might have resulted in lower accuracy than that in our study because our study area is mono-storied with relatively low forest density.

Kwak et al. (2007) detected P. koraiensis (Korean Pine), L. leptolepis (Japanese Larch), and Quercus spp. (Oaks) in a pure forest, with $\mathrm{R}^{2}$ values of $0.68,0.87$, and 0.67 , respectively. Simultaneously, the accuracy assessment for tree heights was also performed with $\mathrm{R}^{2}$ values of 0.77 , 0.80 , and 0.74 , respectively. These results were similar to the results in this study. Pure forest tends to have easier conditions permitting individual tree identification because it is much easier to extract inflection points in mixed forest with various species than in mixed forest. In contrast, Kwak et al. (2007) conducted their study under higher forest density conditions than our study. As previously emphasized in this study, tree detection algorithms are essential in finding the lowest inflection point, which is the treetop. Inflection points tend to be more easily defined in excurrent crown forms when the treetops are sharp. In addition, excurrent crown forms appear primarily in coniferous trees excluding high forest age. Therefore, coniferous trees can show higher accuracy than deciduous trees in finding inflection points.

Kim et al.(2010) detected a stand of even-aged 50-yearold $P$. densiflora using fused aerial image and LiDAR data. Kim et al. (2010) detected 44 and 51 trees with a markercontrolled segmentation and region growing method. These numbers are similar to the 47 on-site tree data in this study.

However, the numbers of well-detected trees ranged from 12 - 32. Although the study area was comprised of pure coniferous forest easily detected than deciduous or mixed forest, it showed relatively low accuracy. This might be because it is difficult to extract inflection points when the crown shape changes from excurrent form to decurrent form due to the increase in stand age. Kim et al. (2010) evaluated and observed tree heights by comparing the results with the average value. Average tree heights in field surveys and LiDAR data were 17.2 and 19.0 - $19.6 \mathrm{~m}$, respectively. However, only average values were considered instead of one to one analysis, which makes it hard to compare our results to their results.

\section{CONCLUSION}

The main objective of this study was to find the location and assess the heights of individual trees using high accuracy airborne LiDAR data. A Fortran program based individual tree detection algorithm was used to redeem the preceding LM filter method limitation. The algorithm used in this this research runs regardless of the window size unlike LM filter. This algorithm generates more accurate de- tection results in comparison to other studies. Four hundred twenty-nine trees were detected in the first step, with average tree height of $12.74 \pm 0.24 \mathrm{~m}$. The height of individual trees was within the $4.05-24.87 \mathrm{~m}$ range having a standard deviation of $4.97 \mathrm{~m}$. The second step assesses the accuracy using field survey and visual interpretation. According to the accuracy assessment by field survey, $87 \%$ of trees were detected. The average tree height error between on-site and LiDAR derived data was $-1.42 \pm 0.64 \mathrm{~m}$ which indicated that the analysis was overestimated. The visual interpretation AI value was $91.35 \%$ with three falsely detected trees and six omitted trees. The average visually interpreted and LiDAR derived data error was $-0.84 \pm 0.10 \mathrm{~m}$, which also indicated the same overestimation as the field survey. The tree height $\mathrm{R}^{2}$ value showed the highest level of accuracy for detecting tree groups ranging from $15-20 \mathrm{~m}$. The same tree ranges were used to compare the visual interpretation and field survey results. $\mathrm{R}^{2}$ values from the field survey and visual interpretation were 0.77 and 0.88 , respectively. Considering that visual interpretation involves high uncertainties depending on the interpreter's accuracy and limited number of on-site sample numbers than visual interpretation, it is considered to have similar detection accuracy.

Note the choice of algorithm and its parameters depending on forest conditions may considerably influence individual tree detection results. We compared our results with the preceding research results to confirm how our algorithm might be influenced by different forest conditions. This study detected $87 \%$ (on-site) trees and showed $91 \%$ AI of visual interpretation, resulting in better performances compared with previous studies. We could finally conclude that the choice of algorithm and its parameters depending on forest conditions may considerably influence detecting individual tree positions. We also found that LiDAR point density is not the only indicator that determines the tree detection result. Future studies should analyze which algorithm generates the best tree detection result depending on the various types of forests under similar LiDAR point density.

Acknowledgements This research was supported by the Korea Forest Service (Grant number S121314L130120) and Chollipo arboretum Bio-Green project.

\section{REFERENCES}

Blundell, S. B., 2008: Local gradient and local maximum analysis of lidar data for tree crown identification. Proceedings of ASPRS 2008 Annual Conference, 12 pp.

Brandtberg, T., T. A. Warner, R. E. Landenberger, and J. B. McGraw, 2003: Detection and analysis of individual leaf-off tree crowns in small footprint, high sampling density lidar data from the eastern deciduous forest in North America. Remote Sens. Environ., 85, 290-303, doi: 10.1016/S0034-4257(03)00008-7. [Link] 
Chave, J., C. Andalo, S. Brown, M. A. Cairns, J. Q. Chambers, D. Eamus, H. Fölster, F. Fromard, N. Higuchi, T. Kira, J. P. Lescure, B. W. Nelson, H. Ogawa, H. Puig, B. Riéra, and T. Yamakura, 2005: Tree allometry and improved estimation of carbon stocks and balance in tropical forests. Oecologia, 145, 87-99, doi: 10.1007/ s00442-005-0100-x. [Link]

Chen, T., J. Morris, and E. Martin, 2006: Probability density estimation via an infinite Gaussian mixture model: Application to statistical process monitoring. J. Roy. Stat. Soc. C Appl. Stat., 55, 699-715, doi: 10.1111/j.14679876.2006.00560.x. [Link]

Clark, M. L., D. B. Clark, and D. A. Roberts, 2004: Smallfootprint lidar estimation of sub-canopy elevation and tree height in a tropical rain forest landscape. Remote Sens. Environ., 91, 68-89, doi: 10.1016/j. rse.2004.02.008. [Link]

Clark, M. L., D. A. Roberts, J. J. Ewel, and D. B. Clark, 2011: Estimation of tropical rain forest aboveground biomass with small-footprint lidar and hyperspectral sensors. Remote Sens. Environ., 115, 2931-2942, doi: 10.1016/j.rse.2010.08.029. [Link]

Cui, G. S., W. K. Lee, W. H. Zhu, J. Lee, H. Kwak, S. Choi, D. A. Kwak, and T. Park, 2012: Vegetation classification and biomass estimation using IKONOS imagery in Mt. ChangBai mountain area. J. kor. For. Soc., 101, 356-364.

Eysn, L., M. Hollaus, E. Lindberg, F. Berger, J. M. Monnet, M. Dalponte, M. Kobal, M. Pellegrini, E. Lingua, D. Mongus, and N. Pfeifer, 2015: A benchmark of Lidarbased single tree detection methods using heterogeneous forest data from the Alpine Space. Forests, 6 , 1721-1747, doi: 10.3390/f6051721. [Link]

Gougeon, F. A., 1995: A crown-following approach to the automatic delineation of individual tree crowns in high spatial resolution aerial images. Can. J. Rem. Sens., 21, 274-284, doi: 10.1080/07038992.1995.10874622. [Link]

Gu, M. R., K. S. Lee, and D. S. Kang, 2010: Image noise reduction using modified Gaussian filter by estimated standard deviation of noise. J. KIIT, 8, 111-117.

Holmgren, J. and Å. Persson, 2004: Identifying species of individual trees using airborne laser scanner. Remote Sens. Environ., 90, 415-423, doi: 10.1016/s0034-4257(03)00140-8. [Link]

Hunter, M. O., M. Keller, D. Victoria, and D. C. Morton, 2013: Tree height and tropical forest biomass estimation. Biogeosciences, 10, 8385-8399, doi: 10.5194/ bgd-10-10491-2013. [Link]

Hyyppä, J., O. Kelle, M. Lehikoinen, and M. Inkinen, 2001: A segmentation-based method to retrieve stem volume estimates from 3-D tree height models produced by laser scanners. IEEE Trans. Geosci. Remote Sensing, 39, 969-975, doi: 10.1109/36.921414. [Link]
IPCC, 2014: Climate Change 2014: Synthesis report. Contribution of Working Groups I, II and III to the Fifth Assessment Report of the Intergovernmental Panel on Climate Change, IPCC, Geneva, Switzerland, $151 \mathrm{pp}$.

Jakubowski, M. K., W. Li, Q. Guo, and M. Kelly, 2013: Delineating individual trees from lidar data: A comparison of vector- and raster-based segmentation approaches. Remote Sens., 5, 4163-4186, doi: 10.3390/ rs5094163. [Link]

Ke, Y. and L. J. Quackenbush, 2011: A review of methods for automatic individual tree-crown detection and delineation from passive remote sensing. Int. J. Remote Sens., 32, 4725-4747, doi: 10.1080/01431161.2010.494184. [Link]

Kim, S. R., D. A. Kwak, W. K. Lee, Y. Son, S. W. Bae, C. Kim, and S. Yoo, 2010: Estimation of carbon storage based on individual tree detection in Pinus densiflora stands using a fusion of aerial photography and LiDAR data. Sci. China Life Sci., 53, 885-897, doi: 10.1007/ s11427-010-4017-1. [Link]

Korea Forest Service (KFS), 2009: Climate Change and Forest, 244 pp. (in Korean)

Korea Forest Service (KFS), 2013: Statistical Yearbook of Forestry, 43 pp. (in Korean)

Kricher, J., 2011: Tropical Ecology, Princeton University Press, New Jerset, USA, 704 pp.

Kwak, D. A., W. K. Lee, J. H. Lee, G. S. Biging, and P. Gong, 2007: Detection of individual trees and estimation of tree height using LiDAR data. J. For. Res., 12, 425-434, doi: 10.1007/s10310-007-0041-9. [Link]

Kwak, D. A., W. K. Lee, H. K. Cho, S. H. Lee, Y. Son, M. Kafatos, and S. R. Kim, 2010: Estimating stem volume and biomass of Pinus koraiensis using LiDAR data. $J$. Plant Res., 123, 421-432, doi: 10.1007/s10265-0100310-0. [Link]

Lamar, W. R., J. B. McGraw, and T. A. Warner, 2005: Multitemporal censusing of a population of eastern hemlock (Tsuga canadensis L.) from remotely sensed imagery using an automated segmentation and reconciliation procedure. Remote Sens. Environ., 94, 133-143, doi: 10.1016/j.rse.2004.09.003. [Link]

Leckie, D., F. Gougeon, D. Hill, R. Quinn, L. Armstrong, and R. Shreenan, 2003: Combined high-density lidar and multispectral imagery for individual tree crown analysis. Can.J. Rem. Sens., 29, 633-649, doi: 10.5589/ m03-024. [Link]

Lee, S., 2008: Application of Hyperspectral Image Data for Vegetation Analysis, Korea Environment Institute, pp. 83. (in Korean)

Magnussen, S. and P. Boudewyn, 1998: Derivations of stand heights from airborne laser scanner data with canopybased quantile estimators. Can.J. For. Res., 28, 10161031, doi: 10.1139/x98-078. [Link]

Næsset, E. and T. Økland, 2002: Estimating tree height and 
tree crown properties using airborne scanning laser in a boreal nature reserve. Remote Sens. Environ., 79, 105115, doi: 10.1016/s0034-4257(01)00243-7. [Link]

Park, T., J. Y. Lee, W. K. Lee, D. A. Kwak, H. B. Kwak, and S. Lee, 2011: Automated individual tree detection and crown delineation using high spatial resolution RGB aerial imagery. Kor. J. Rem. Sens., 27, 703-715, doi: 10.7780/kjrs.2011.27.6.703. [Link]

Park, T., J. K. Cho, J. Y. Lee, W. K. Lee, S. Choi, D. A. Kwak, and M. I. Kim, 2014: Unconstrained approach for isolating individual trees using high-resolution aerial imagery. Int. J. Remote Sens., 35, 89-114, doi: 10.1080/01431161.2013.862603. [Link]

Persson, A., J. Holmgren, and U. Söderman, 2002: Detecting and measuring individual trees using an airborne laser scanner. Photogramm. Eng. Rem. Sens., 68, 925-932.

Popescu, S. C., 2007: Estimating biomass of individual pine trees using airborne lidar. Biomass and Bioenergy, 31, 646-655, doi: 10.1016/j.biombioe.2007.06.022. [Link]

Popescu, S. C., R. H. Wynne, and R. F. Nelson, 2002: Estimating plot-level tree heights with lidar: Local filtering with a canopy-height based variable window size. Comput. Electron. Agric., 37, 71-95, doi: 10.1016/ s0168-1699(02)00121-7. [Link]

Pouliot, D. A., D. J. King, F. W. Bell, and D. G. Pitt, 2002: Automated tree crown detection and delineation in high-resolution digital camera imagery of coniferous forest regeneration. Remote Sens. Environ., 82, 322334, doi: 10.1016/s0034-4257(02)00050-0. [Link]

Rahman, M.Z. A. and B. G. H. Gorte, 2009: Tree crown delineation from high resolution airborne LiDAR based on densities of high points. Proceedings ISPRS Workshop Laserscanning 2009, September 1-2, France, IAPRS, XXXVIII (3/W8).

Singh, I. J., L. Squire, and J. Strauss, 1986: Agricultural Household Models: Extensions, Applications, and Policy, Johns Hopkins University Press, Baltimore, MD, $335 \mathrm{pp}$.

St-Onge, B. A., 1999: Estimating individual tree heights of the boreal forest using airborne laser altimetry and digital videography. Int. Arch. Photogram. Rem. Sens.
Spatial Inform. Sci., 32, 179-184.

Tubiello, F. N., M. Salvatore, A. F. Ferrara, J. House, S. Federici, S. Rossi, R. Biancalani, R. D. C. Golec, H. Jacobs, A. Flammini, P. Prosperi, P. Cardenas-Galindo, J. Schmidhuber, M. J. S. Sanchez, N. Srivastava, and P. Smith, 2015: The contribution of agriculture, forestry and other land use activities to global warming, 1990-2012. Global Change Biol., 21, 2655-2660, doi: $10.1111 / \mathrm{gcb} .12865$. [Link]

Vasilescu, M. M., 2013: Standard error of tree height using Vertex III. Bulletin of the Transilvania University of Braşov, Series II: Forestry, Wood Industry, Agricultural Food Engineering, Vol. 6, 75-80.

Vauhkonen, J., L. Ene, S. Gupta, J. Heinzel, J. Holmgren, J. Pitkänen, S. Solberg, Y. Wang, H. Weinacker, K. M. Hauglin, V. Lien, P. Packalén, T. Gobakken, B. Koch, E. Næsset, T. Tokola, and M. Maltamo, 2012: Comparative testing of single-tree detection algorithms under different types of forest. Forestry, 85, 27-40, doi: 10.1093/forestry/cpr051. [Link]

Wang, Z., A. C. Bovik, H. R. Sheikh, and E. P. Simoncelli, 2004: Image quality assessment: From error visibility to structural similarity. IEEE Trans. Image Process., 13, 600-612, doi: 10.1109/tip.2003.819861. [Link]

Warner, T. A., J. Y. Lee, and J. B. McGraw, 1998: Delineation and identification of individual trees in the eastern deciduous forest. In: Hill, D. A. and D. G. Lecki (Eds.), Automated Interpretation of High Spatial Resolution Digital Imagery for Forestry, Victoria, British Columbia, Canada, February 10-12, 81-91.

Yoon, J. S., K. S. Lee, J. I. Shin, and C. S. Woo, 2006: Characteristics of airborne Lidar data and ground points separation in forested area. Kor. J. Rem. Sens., 22, 533-542.

Yoon, M., 2015: Extraction of individual trees and estimation of above ground biomass in intact tropical rain forest of Brunei using airborne LiDAR data. Master Thesis, Korea University, Korea.

Zhang, C., Y. Zhou, and F. Qiu, 2015: Individual tree segmentation from LiDAR point clouds for urban forest inventory. Remote Sens., 7, 7892-7913, doi: 10.3390/ rs70607892. [Link] 